\title{
Minimization of Transportation Cost Problems
}

\author{
Shammah Sunday Kpanja ${ }^{1 *}$ Atama Alhamdu Madaki ${ }^{2}$ \\ $1 \& 2$ Department of Mathematics And Statistics, Nasarawa State Polytechnic, Lafia \\ P.M.B 109, Lafia, Nasarawa State, Nigeria
}

The research is financed by Tertiary Education Trust Fund (TETFund). No. 6 Zambezi Crescent, Maitama, Abuja, Nigeria.

\begin{abstract}
This paper present seven initial methods of solving transportation problems. These methods were compared on a balanced transportation model of Dangote's Cement Factories and the result shows that the Vogel's method yields the best starting solution and gives an initial solution as the optimal with zero number of iteration. The North-West Corner Method although fast in obtaining the initial solution is not very efficient and accurate enough in finding initial solution as it pays no attention to the unit cost particularly as the solution is far from the optional. The objective value for the initial basic feasible solutions obtained from Russel's and Row-Minimum Method are in perfect agreement.
\end{abstract}

Keywords: Linear Programming, Transportation, Initial Solution, Minimization.

DOI: $10.7176 / \mathrm{MTM} / 9-3-03$

Publication date: March $31^{\text {st }} 2019$

\section{Introduction}

A transportation problem is one of the sub-class of a linear programming problems where the objective is to transport various quantities of single homogenous product that are initially stored at various origin to different destinations in such a way that the total transportation cost is minimized (Taha 1995).

Whenever there is a physical movement of goods from the point of manufacturing to final consumer through a variety of channels of distribution, there is need to minimize the cost of transportation so as to increase the profit on sales. Transportation problem arises in all such cases and they aim at providing assistance to the top management in ascertaining how many units of a particular product should be transported from each supply origin to each demand destination so that the total prevailing demand for the company product is satisfied and at the same time transportation cost is minimized (Sharma 1997).

Transportation problem can be generalized into transshipment problem where shipment is possible from origin $i$ to destination $j$. Transshipment can be formulated as a transportation problem with an increase number of origins and destinations (Kapoor 1997).

The general method of solution for a transportation problems is first to establish the problem matrix with each origin as a row and each destination as a column. Also an initial solution must be obtained that satisfied all constraints on the matrix model. A matrix with $m$ origins and $n$ destinations will have $m+n-1$ quantities of goods shipped from origin $i$ to destination $j$. A test is performed on the matrix to see if there exist solutions that will provide a lower total cost to the company. If one exists, a new solution is found and this new solution is in turn tested for a possible better solution. Each solution which is tested and the new solution formed is called an 
iteration. On a large scale, thousand of iterations may be required before an optimal solution can be obtained (Ocheche et al 2016).

\section{Formulation of the Transportation Problem}

Given $\mathrm{m}$ origin and $\mathrm{n}$ destinations, the transportation problem can be formulated as the following programming model

$\operatorname{Minimize} \mathrm{Z}=\sum_{i=1}^{\mathrm{m}} \sum_{j=1}^{\mathrm{n}} C_{i j} \mathrm{x}_{i j}$

Subject to

$$
\begin{aligned}
& \sum_{\mathrm{I}=\mathrm{I}}^{\mathrm{n}} \mathrm{X}_{i \mathrm{j}}=a_{i} \text { for }_{i=1} 1,2, \ldots, \mathrm{m} \\
& \sum_{i=\mathrm{I}}^{\mathrm{m}} \mathrm{X}_{i \mathrm{j}}=\mathrm{bj}_{\text {for }} \mathrm{j}=1,2, \ldots, \mathrm{n}
\end{aligned}
$$

and

$$
\mathrm{X}_{i \mathrm{j}} \geq \mathrm{o} \text { for all } i \text { and } j
$$

Where $\mathrm{X}_{i \mathrm{j}}$ is the amount of units shipped from origin $i$ to destination $\mathrm{j}$ and $\mathrm{C}_{i \mathrm{j}}$ is the cost of shipping one unit from origin $i$ to destination $\mathrm{j}$.

The amount of supply at origin is $a_{i}$ and the amount at destination is $b_{\mathrm{j}}$. The objective is to determine the unknown $\mathrm{X}_{i \mathrm{j}}$ that will minimized the total transportation cost while satisfying all the supply and demand constraints (Ocheche et al 2016).

\subsection{Balanced Transportation Problem}

If the sum of the supplies of all the sources is equal to the sum of the demand of all the destinations, then the problem is termed as a Balanced Transportation problem. Here

$\sum_{i=1}^{\mathrm{m}} a_{i}=\sum_{j=1}^{\mathrm{n}} b_{j}$

\subsection{Unbalanced Transportation Problem}

If the sum of the supplies of all the sources is not equal to the sum of the demands of all the destinations then the problem is termed as unbalanced transportation problems. Here 


$$
\sum_{i=1}^{\mathrm{m}} a_{i}=\sum_{j=1}^{\mathrm{n}} b_{j}
$$

An unbalanced transportation problem can be modified to a balanced one by introducing a dummy sink if

$$
\sum_{i=1}^{\mathrm{m}} a_{i}>\sum_{j=1}^{\mathrm{n}} b_{j} \quad \text { And a dummy source if } \quad \sum_{i=1}^{\mathrm{m}} a_{i}<\sum_{j=1}^{\mathrm{n}} b_{j}
$$

The inflow from the source to a dummy sink represents the surplus at the source. Similarly the flow from a dummy source to a sink presents the unfulfilled demand at the sink. The cost of transporting a unit from a dummy source to a dummy sink is assumed to be zero. The resulting problem is now balanced and be solved.

\section{Solving Transportation Problem of Dangote's Cement Industries}

Dangote group of company has a number of cement production plants. This research is focused on three of these plants; Dangote Cement Factory located at Gboko, Objana and Ibesse and the company's depots and wholesale outlets in cities of Lafia, Abuja, Jos and Minna.

Dangote Transport Company ships truckloads of cement from three factories to four warehouses. The supply (in truckloads) and the demand (also in truckloads) together with the unit transportation costs per truckload on the different routes are summarized in the transportation model in Table 1.

The model seeks the minimum-cost shipping schedule between the factories and the warehouses. This is equivalent to determining the quantity $\mathrm{X}_{i \mathrm{j}}$ shifted from factory $i$ to warehouse $j(i=1,2,3: j=1,2,3,4)$.

Table1. Supply and demand with unit transportation cost

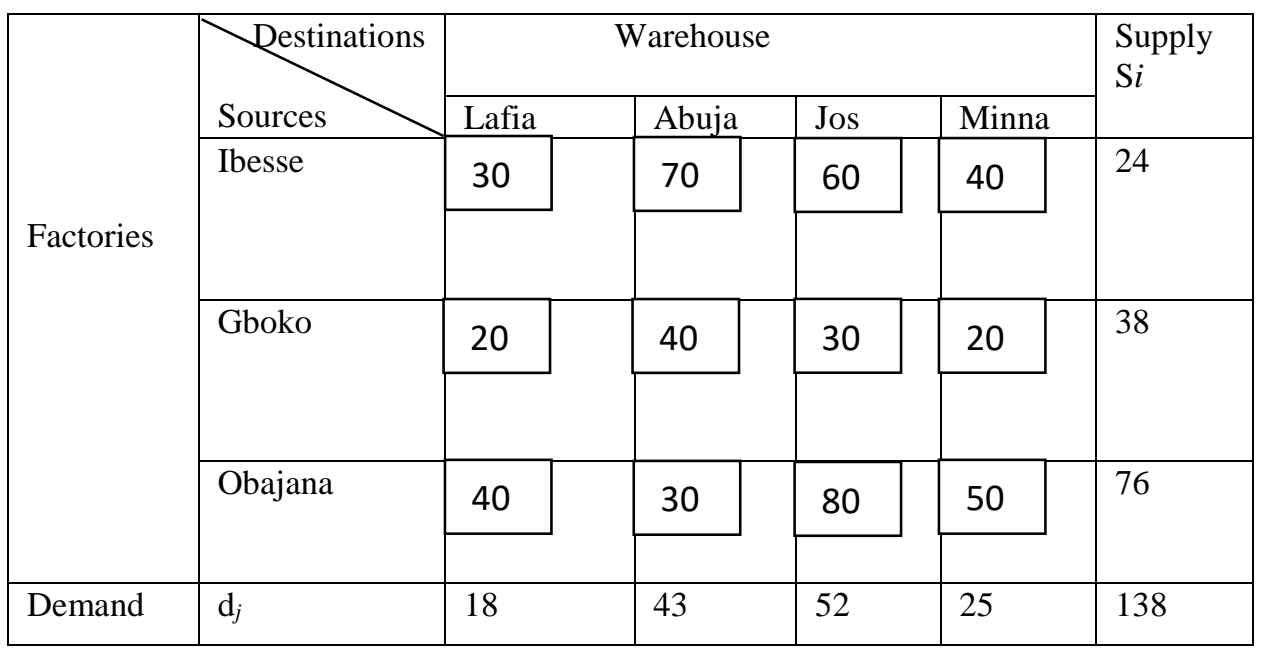




\section{Methods for Finding Initial Solution Used in the Research}

Seven initial methods were used to solve transportation problems from Dangote Cement Factories and a brief explanation on each of the methods is as follows:

\subsection{North-West Corner Method (NWC)}

This method starts at the northwest corner cell or upper left corner cell of a transportation table. It allocates as much as possible to the selected cell and adjust the associated amount of supply and demand by subtracting the allocated amount. This results in crossing out a row or column.

If exactly one row or column is left uncrossed out, we stop, otherwise, we move to the cell which is to the right if a column has just been crossed out or below if a row has been crossed out (Taghrid et al 2009). We denote this method as M 1 for the purpose of this research.

\subsection{Least Cost Method}

The Least Cost Method finds a better starting solution by concentrating on the cheapest routes. The method starts by assigning as much as possible to the cell with the smallest unit cost. Next, the satisfied row or column is crossed out and the supply and demand are adjusted accordingly. We next look for the uncrossed out cell with smallest unit cost and repeat the process until exactly one row or column is left uncrossed (Taghrid et al 2009) We denote this method as M2 for the research purpose.

\subsection{Vogel's Approximation Method(Vam)}

Vogel's Approximation Method, denoted as M3 in this research, is an improved version of the least cost method that generally has been obtained to produce better starting solutions. It has been claimed to be the best initial method (John et al 2001). The complete steps in implementing the methods are as follows:

Step 1: $\quad$ For each row (column) determine a penalty measure by subtracting the smallest unit cost element in the row (column) from the next smallest unit cost element in the same row (column).

Step II: Identify the row or column with the largest penalty, breaking ties arbitrarily. Allocate as much as possible to the variable with the least unit cost in the identified row or column, adjust the supply and demand and cross out the satisfied row or column. If a row and a column are satisfied simultaneously, one of the two is crossed out and the remaining row (column) is assigned zero supply (demand). 
Step III: (a) If exactly one row or column with zero supply or demand (column) remains uncrossed out stop.

(b) If one row (column) with positive supply remains uncrossed out, determine the basic variables in the row (column) by the least cost method. Stop.

(c) If all the uncrossed out rows and columns have (remaining) zero supply and demand, determine the zero basic variables by the least-cost method. Stop.

(d) Otherwise go to step (I) (Kapoor 1997)

\subsection{Row-Column Minimum Method}

Row-Column Minimum method is a combination of both row and column minimum methods. It is developed in this research with the intention of taking the advantages of the two methods. It starts with allocation in the first row and first column simultaneously choosing the lowest cost cells one after the other of the first row or column so that the capacities of the first supply and first demand are both satisfied. Next the satisfied row and column are both crossed out, and the amount of supply and demand are adjusted accordingly. The method next considers allocation in the second row and second column, choosing the lowest cost cells and repeating the process until exactly both the capacities of the columns and the rows are exhausted. This method is denoted as M4.

\subsection{Column Minimum Method}

Column Minimum Method denoted as M5 in the research, starts with first column and chooses the lowest cost cell of first column so that either the demand of the fist distribution centre is satisfied or the capacity of the $i^{\text {th }}$ supply is satisfied or both. Three eases arise as follows:

i. If the demand of the first distribution centre is satisfied cross out the first column and move right to the second column.

ii. If the capacity of $i^{\text {th }}$ supply is satisfied, cross out the $i^{\text {th }}$ row and reconsider the first column with the remaining demand.

iii. If the demands of the first distribution centre as well as the capacity of the $\mathrm{i}^{\text {th }}$ supply are completely satisfied, cross out the column as well as the $\mathrm{i}^{\text {th }}$ row and move right to the second column.

Continue the process for the resulting reduced transportation table until the last column (John et al 2001). 


\subsection{Russell's Approximation Method}

Russell's approximation method, denoted as M6, is a more recently proposed method that seems very promising. Computation takes a longer time because each cell is involved or considered. The complete steps followed in implementing the method are as follows:

Step I: For each source i remaining under consideration determine its $u_{i}$ which is the largest cost $\left(c_{i j}\right)$ still remaining in that row.

Step II: For each destination column $\mathrm{j}$ remaining under consideration, determine its $\mathrm{v}_{\mathrm{j}}$ which is the largest unit $\operatorname{cost}\left(\mathrm{c}_{\mathrm{ij}}\right)$ still remaining in that column.

Step III: For each variable $x_{i j}$ not previously selected in these rows and columns, calc $\Delta_{a t e} i j=C_{i j}-U_{i}-V_{j}$. Allocation is then made to the cell having the largest neg®ive value of $\quad$ ij. At The allocation will result in crossing out a row or a column, according as to whether the supply in the row or the demand in the column is satisfied. The process is repeated until all demands and supplies are satisfied.

\subsection{Row Minimum Method}

denoted as M7 in the research, starts with the first row and chooses the lowest cost cell in the row so that either the capacity of the first supply is exhausted or the demand of the $\mathrm{j}^{\text {th }}$ distribution centre is satisfied or both. Three cases arise as follows.

i. If the capacity of the first supply is completely satisfied, cross out the first row and proceed to the second row.

ii. If the demand at $\mathrm{j}^{\text {th }}$ distribution centre is satisfied, cross out the $\mathrm{j}^{\text {th }}$ column and reconsider the first row with the remaining capacity.

iii. If the capacity of the first supply as well as demand at $\mathrm{j}^{\text {th }}$ distribution centre are completely satisfied, cross out the row as well as the column and move down to the second row.

Continue this process for the resulting reduced transportation table units until the last row (John et al 2001) The above seven initial methods were applied to the Dangote Company in table 1 as follows: 
Table 3. The Starting Solution using North West Corner Method $\left(\mathrm{M}_{1}\right)$

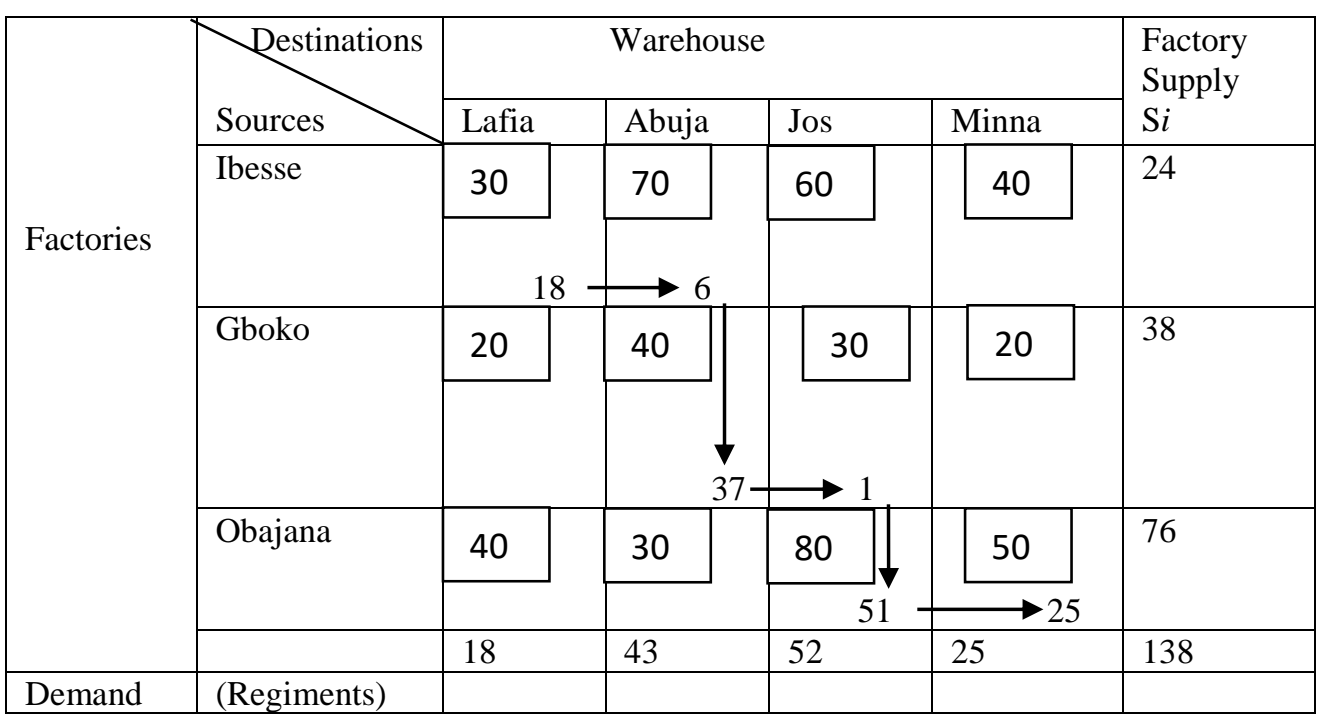

The initial basic feasible solution is obtained as follows:

$$
\begin{aligned}
& \text { Min } \mathrm{Z}=\sum_{i=1}^{m} \sum_{j=1}^{\mathrm{n}} \mathrm{C}_{i \mathrm{j}} \mathrm{X}_{i \mathrm{j}} \\
& \mathrm{Z}=30 \mathrm{X}_{11}+70 \mathrm{X}_{12}+40 \mathrm{X}_{22}+30 \mathrm{X}_{23}+80 \mathrm{X}_{33}+50 \mathrm{X}_{34} \\
& =\geqq 7,800
\end{aligned}
$$

Table 3. The Starting Solution using least cost Mothod $\left(\mathbf{M}_{2}\right)$

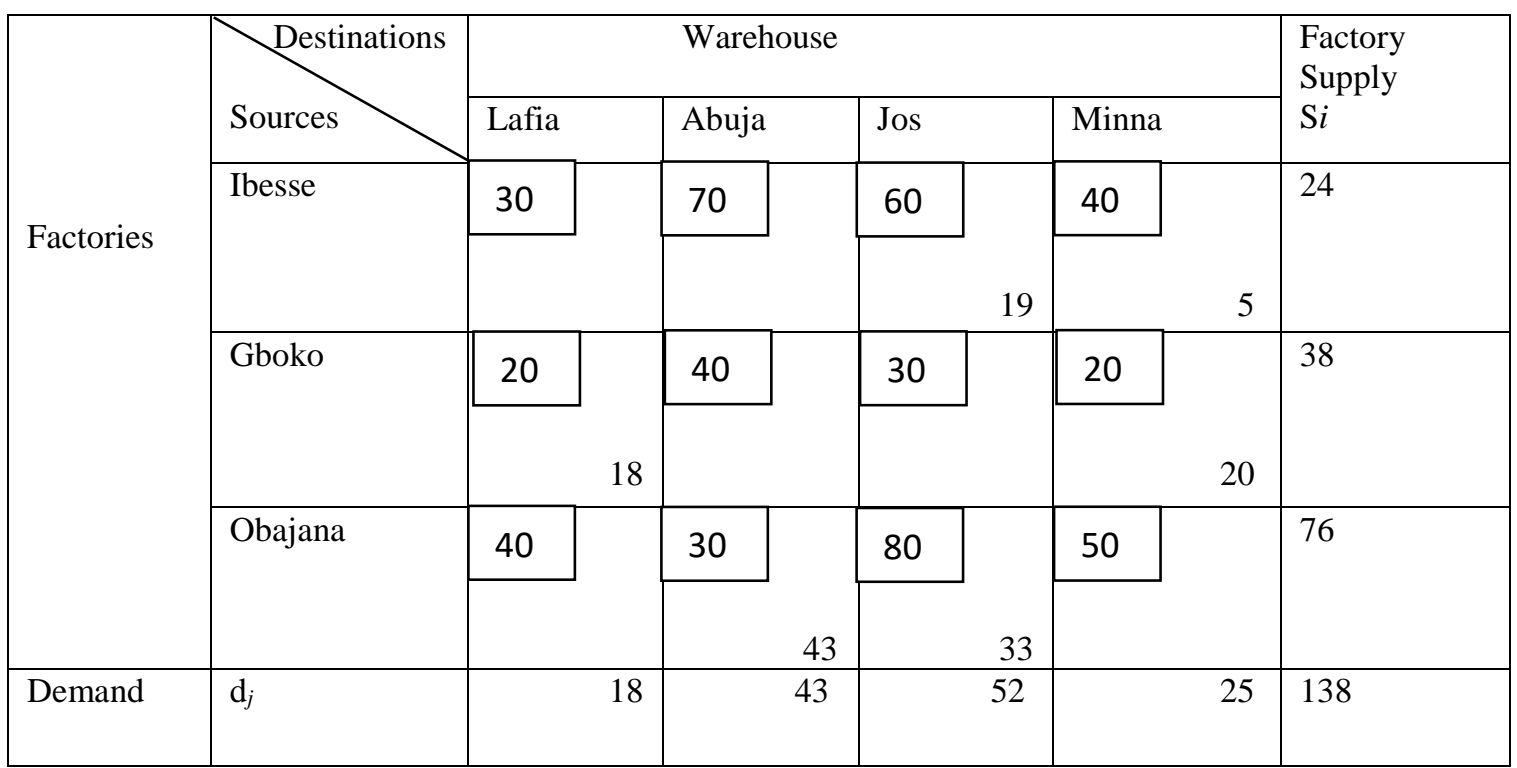

From the basic feasible solution, the total transportation 
Cost $\mathrm{Z}=\sum_{i=1}^{m} \sum_{j=1}^{\mathrm{n}} \mathrm{C}_{i \mathrm{j}} \mathrm{X}_{i \mathrm{j}}$ is obtained as follows

$Z=60 X_{13}+40 X_{14}+20 X_{21}+20 X_{24}+30 X_{32}+80 X_{33}$

$=\$ 6,030$

Table 4. The starting Solution using Vogel's Method $\left(\mathrm{M}_{3}\right)$

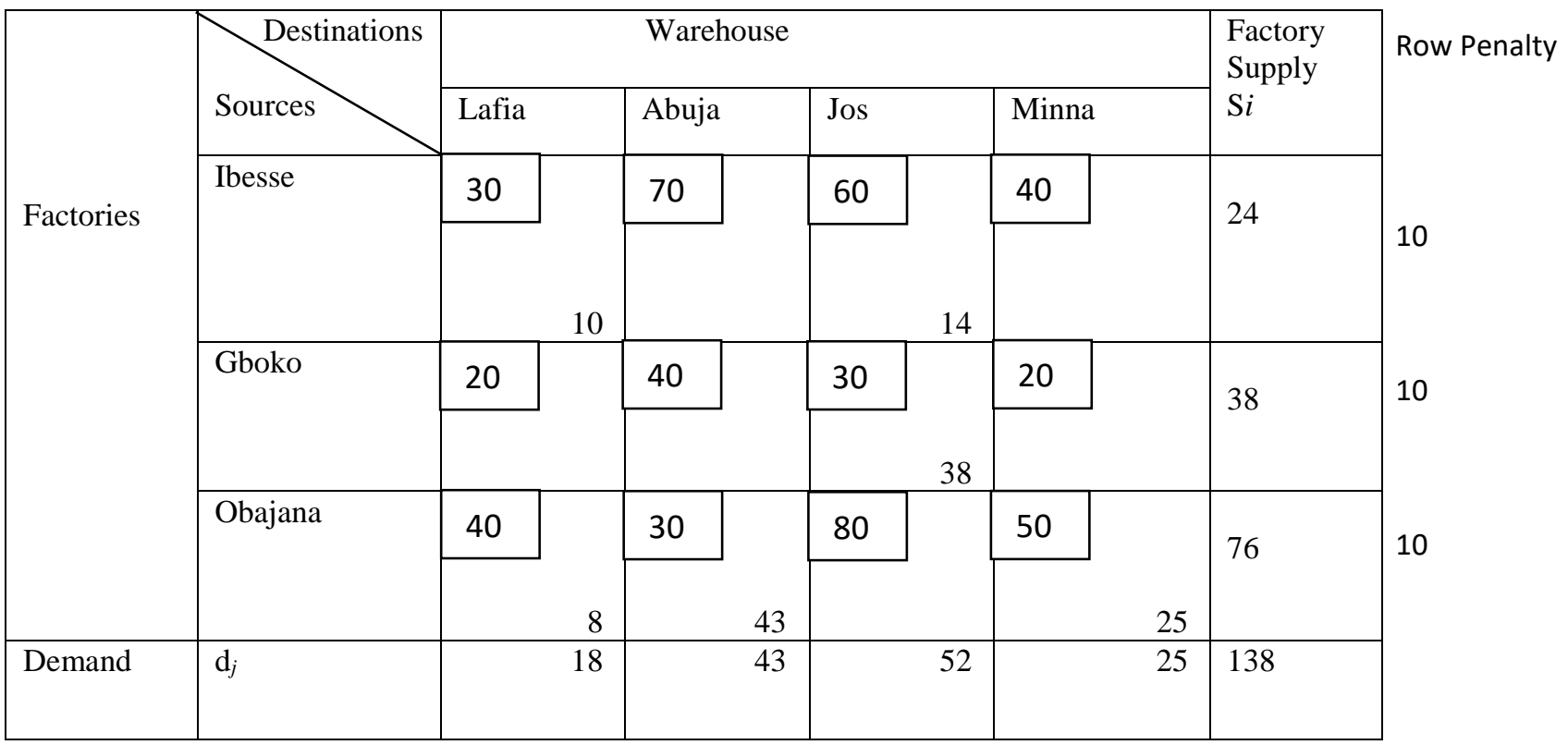

From thel hmptaPbasityfeasible solution, is obtained as follows:

30

20

Cost $\mathrm{Z}=\sum_{i=1}^{m} \sum_{j=1}^{\mathrm{n}} \mathrm{C}_{i \mathrm{j}} \mathrm{X}_{i \mathrm{j}}$

$Z=30 X_{11}+60 X_{13}+30 X_{23}+40 X_{31}+30 X_{32}+50 X_{34}$

$\mathrm{Z}=\$ 5,140$ 
Table 5. The Starting Solution Using Row-Column Minimum Method ( $\left.\mathrm{M}_{4}\right)$

\begin{tabular}{|c|c|c|c|c|c|c|c|c|c|}
\hline \multirow{8}{*}{ Factories } & Destinations & \multicolumn{7}{|c|}{ Warehouse } & \multirow{2}{*}{$\begin{array}{l}\text { Factory } \\
\text { Supply } \\
\text { Si }\end{array}$} \\
\hline & Sources & \multicolumn{2}{|c|}{ Lafia } & Abuja & \multicolumn{2}{|l|}{ Jos } & \multicolumn{2}{|c|}{ Minna } & \\
\hline & Ibesse & 30 & \multirow[b]{2}{*}{18} & 70 & 60 & & 40 & \multirow[b]{2}{*}{6} & 24 \\
\hline & & & & & & & & & \\
\hline & Gboko & 20 & & 40 & 30 & & 20 & \multirow[b]{2}{*}{19} & 38 \\
\hline & & & & & & & & & \\
\hline & \multirow[t]{2}{*}{ Obajana } & 40 & & 30 & 80 & \multirow[b]{2}{*}{52} & 50 & & \multirow[t]{2}{*}{76} \\
\hline & & & & & & & & & \\
\hline Demand d & & & 18 & & & 52 & & 25 & \\
\hline
\end{tabular}

The Initial Basic Feasible Solution is obtained as follows:

Cost $\mathrm{Z}=\sum_{i=1}^{m} \sum_{j=1}^{\mathrm{n}} \mathrm{C}_{i \mathrm{j}} \mathrm{X}_{i \mathrm{j}}$

$Z=30 X_{11}+40 X_{14}+40 X_{22}+20 X_{24}+30 X_{32}+80 X_{33}$

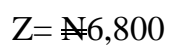

Table 6. The Starting Solution Using Column-Minimum Method ( $\left.\mathbf{M}_{5}\right)$

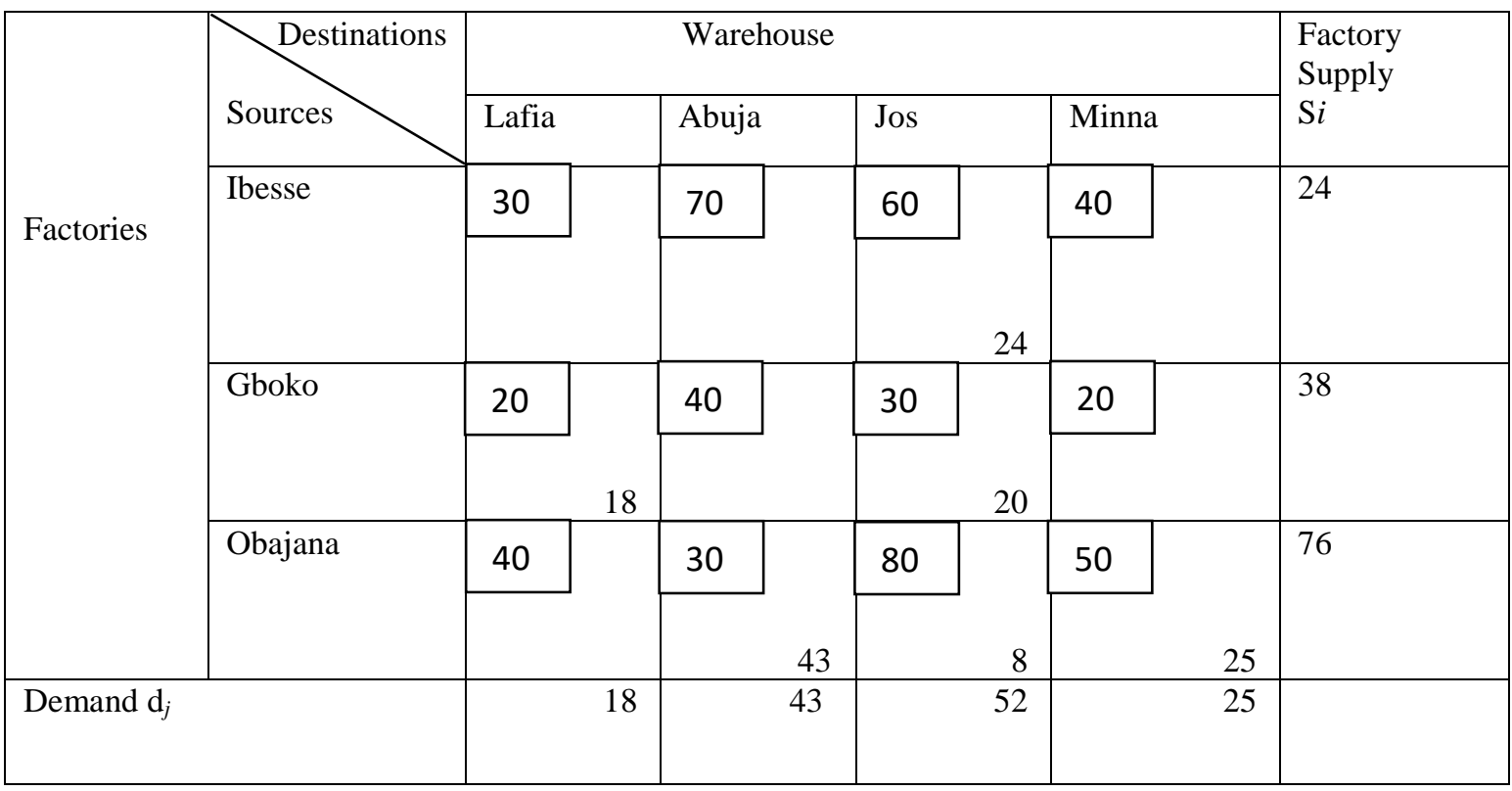


The Initial Basic Feasible Solution is obtained as follows:

Cost $\mathrm{Z}=\sum_{i=1}^{m} \sum_{j=1}^{\mathrm{n}} \mathrm{C}_{i \mathrm{i}} \mathrm{X}_{i \mathrm{i}}$

$Z=60 X_{13}+20 X_{21}+30 X_{13}+30 X_{32}+80 X_{33}+50 X_{34}$

$\mathrm{Z}=\$ 5,580$

Table 7. The Starting Solution Using Russell's Method $\left(\mathrm{M}_{6}\right)$

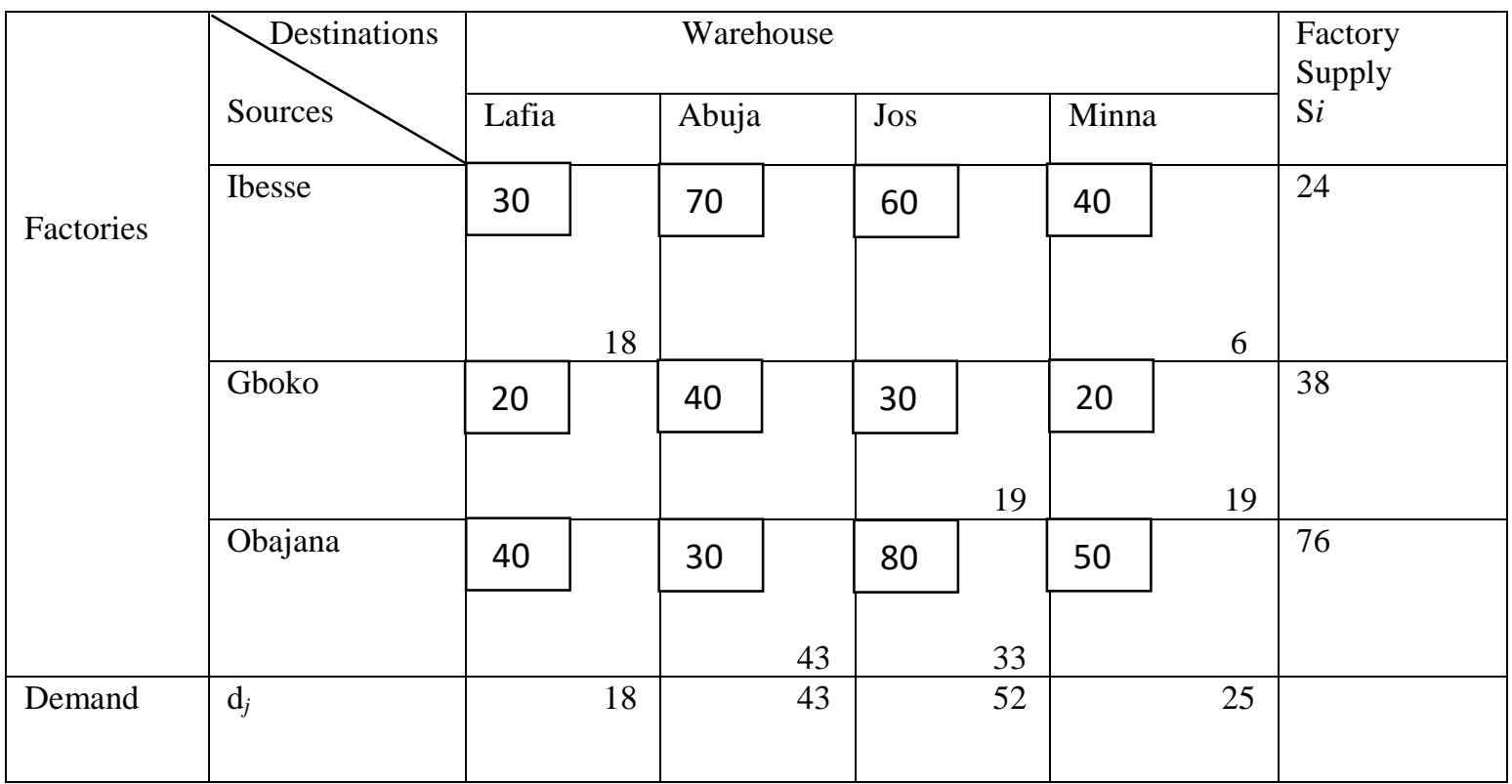

The Initial Basic Feasible Solution is obtained as follows:

Cost $\mathrm{Z}=\sum_{i=1}^{m} \sum_{j=1}^{\mathrm{n}} \mathrm{C}_{i \mathrm{j}} \mathrm{X}_{i \mathrm{j}}$

$\triangle_{i j}=\mathrm{C}_{i \mathrm{j}}-\mathrm{U}_{i}-\mathrm{V}_{\mathrm{j}}$

$Z=30 X_{11}+40 X_{14}+30 X_{23}+20 X_{24}+30 X_{32}+80 X_{33}$

$Z=\$ 5,660$ 
Table 8. The starting Solution Using Row-minimum Method $\left(\mathrm{M}_{7}\right)$

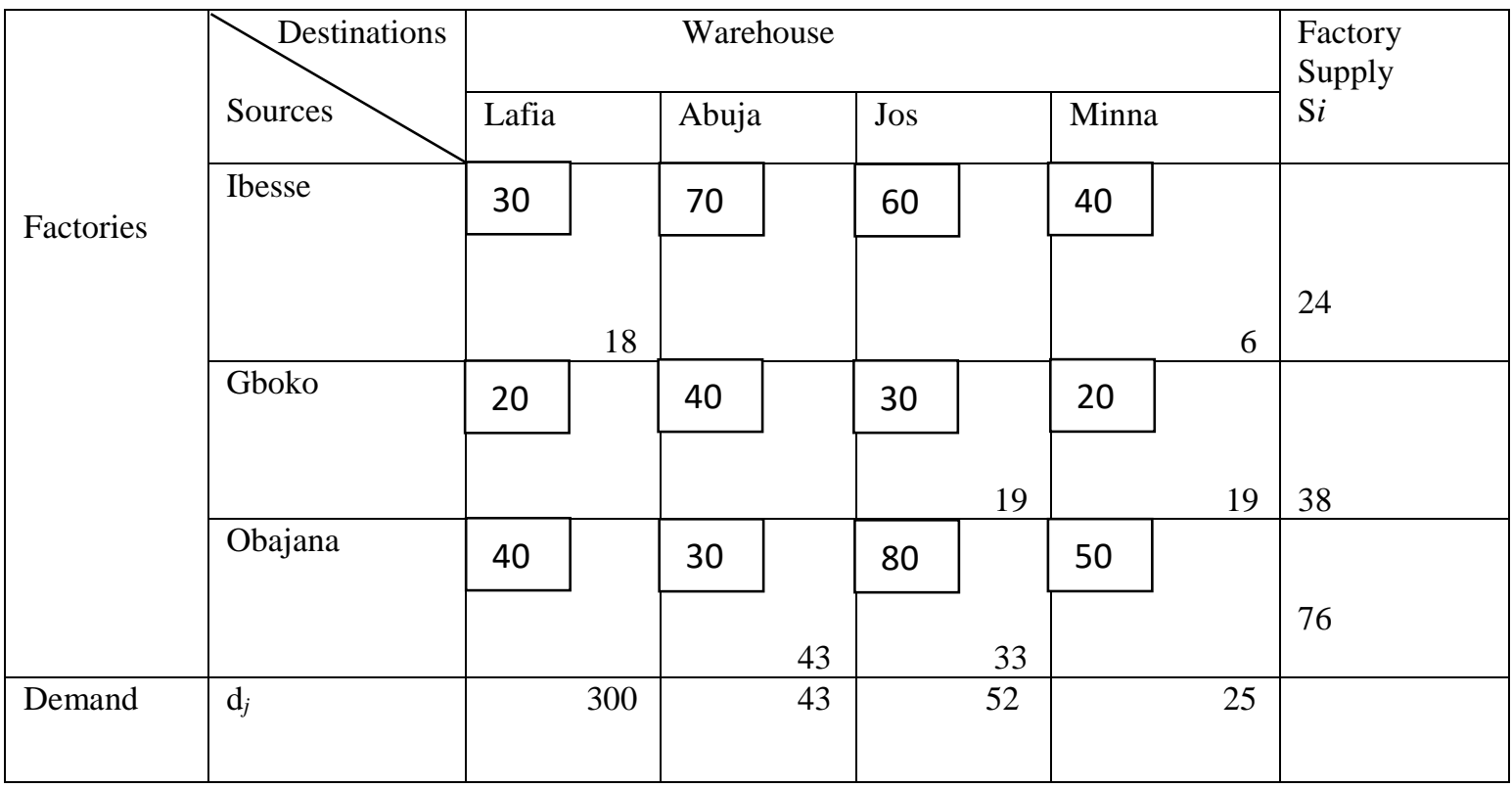

The Initial Basic Feasible Solution is obtained as follows:

Cost $\mathrm{Z}=\sum_{i=1}^{m} \sum_{j=1}^{\mathrm{n}} \mathrm{C}_{i \mathrm{j}} \mathrm{X}_{i \mathrm{j}}$

$Z=30 X_{11}+40 X_{14}+30 X_{23}+20 X_{24}+30 X_{32}+80 X_{33}$

$Z=\$ 5,660$

\section{Comparison between the Initial Methods}

Table 9. Comparism of result between the initial Methods

\begin{tabular}{lccc}
\hline Methods & Initial Feasible Solution & Optional & Number of Iterations \\
\hline North West Corner Method (M1) & 7800 & 5140 & 3 \\
Least Cost Method (M2) & 6030 & 5140 & 0 \\
Vogel Method (M3) & 5140 & 5140 & 4 \\
Row-Column Minimum Method (M4) & 6800 & 5140 & 2 \\
Column Minimum Method (M5) & 5580 & 5140 & 3 \\
Russel Method (M6) & 5660 & 5140 & 3 \\
Row-Minimum Method (M7) & 5660 & 5140 & \\
\hline
\end{tabular}




\section{Discussion of the Result}

The seven initial methods differ in the quality of the starting basic solution they produce in the sense that a better starting solutions yields a smaller objective value. The main virtue of the North-West Corner Method is that it is quick and easy, however it pays no attention to the unit cost usually the result is far from the optimal. Vogel's Method yields the best starting solution and gives an initial solution as the optimal. Row-Column Minimum Method, even though sensitive to unit cost, is not very efficient and accurate enough in finding the initial feasible solution. It takes four numbers of iterations to give an optional solution. Column- Minimum Method takes two number of iterations to give an optimal solution but the initial solution is not as good as Vogel's Method.

Russel's and Row-Minimum methods yield the same initial solution but Russel's method differ from RowMinimum method in the sense that it is slow in implementing it's step because computation takes a longer time. The objective function of the Least Cost Method is more than the Vogel's method and it takes four numbers of iterations to give an optimal solution.

\section{Conclusion}

The research has shown that the Vogel's (M3) method gives the best initial methods for a transportation problem; it provides a lower total cost for the company. Therefore production and marketing managers of Dangote's cement factories may adopt the method so as to maximized profit and also the designers of software of transportation problems may use the method in their packages.

\section{References}

John D. McGregor, David A. Sykes (2001). "A practical guide to testing object-oriented software. Addison Wesley Professional USA".

Kapoor V.K (1997), “Operations Research Techniques for Management”, Sultan Chand and Sons, New Delhi

Ocheche A. P., Ayodele O. and Peter, B. (2016). "On the comparative study of initial basic feasible solution methods for transportation problem using Tempering Ordered Algorithm as a validation tool ". Journal of the Nigerian Mathematical Physics 36 (2), 429-436.

Sharma. J.K (1997) “Operation Research problem and solution”, Macmillan India, New Delhi

Taghrid. I.S Gaber I and Mohammad G. (2009). "Solving Transportation Problem using Object oriented Model”. International Journal of Computer Science and Network Security 9 (2), 353-361.

Taha M A (1995), "Introduction to Operational Research Prentice". Hall, New Delhi. 